\title{
Biblia e iglesia, a la luz de la Lumen Gentium"
}

\author{
Ana Francisca Vergara Abril ${ }^{* *}$ \\ Recibido: 04 de octubre de 2016 • Aprobado: 01 de noviembre de 2016. \\ “Encontramos a Jesús en la Sagrada Escritura, leída en Iglesia. \\ La Sagrada Escritura, "Palabra de Dios \\ escrita por inspiración del Espíritu Santo", \\ es, con la Tradición, fuente de vida para la Iglesia \\ y alma de su acción evangelizadora". DA, 247
}

\section{Resumen}

En este artículo de reflexión se presenta un acercamiento a la constitución dogmática Lumen Gentium del Concilio Vaticano II desde un horizonte bíblico, se divide en tres grandes apartados en los cuales se presentan diferentes visiones del concepto 'iglesia', a saber: biblia e iglesia, las imágenes bíblicas de la iglesia y de una pastoral de mera conservación a una pastoral decididamente misionera; el texto parte desde una conceptualización especializada para terminar en la labor evangelizadora y pastoral.

Palabras clave: Lumen Gentium, iglesia, biblia, pastoral, concilio Vaticano II.

* Este artículo reflexivo es un fragmento de las investigaciones particulares de la autora.

* Bachiller y Licenciada en Misionología, Pontificia Universidad Urbaniana, Roma; Especialización en Formación Vocacional, Instituto de Metodología Pedagógica, Pontificia Universidad Salesiana, Roma; e Instituto para Formadores del Clero, IFEC, Conferencia Episcopal Francesa, París; Diploma de Formación Bíblica, Studium Biblicum Franciscanum, IBF, Jerusalén. Religiosa dominica de la Presentación, misionera y formadora en Camerún, Costa de Marfil, Burkina Faso, Francia y Jerusalén. Correo electrónico: anafranciscavergara@yahoo.es 


\title{
Bible and church, in the light of Lumen Gentium
}

\begin{abstract}
In this reflection article we present an approach to the Dogmatic Constitution Lumen Gentium of the Second Vatican Council from a biblical horizon. It is divided into three main sections in which different visions of the concept of 'church' are presented: bible and church, biblical images of the church and of a pastoral of mere conservation to a decidedly missionary pastoral; the paper starts from a specialized conceptualization to end in the evangelizing and pastoral work.
\end{abstract}

Keywords: Lumen Gentium, church, bible, pastoral, Second Vatican Council.

\section{Bible et église à la lumière de la Lumen Gentium}

\section{Résumé}

Cet article, qui présente une approche à la Constitution dogmatique Lumen Gentium du Concile Vatican II à partir d'un horizon biblique, est divisé en trois sections principales dans lesquelles sont présentées différentes visions de la notion d' «église», à savoir: bible et église, les images bibliques de l'église et d'une pastorale de pleine préservation à une pastorale résolument missionnaire; le texte débute avec une conceptualisation spécialisée et termine avec le travail évangélisateur et pastoral.

Mots-clés: Lumen Gentium, église, bible, pastoral, Concile Vatican II.

\section{Introducción}

Acercarse a un texto después de cincuenta años de su promulgación pide desplazarse en el tiempo y hacer un poco de ejercicio mental para comprender el lenguaje en el que está escrito y por consiguiente entender el contexto en el que fue redactado. Podemos pensar lo mismo acerca de los documentos conciliares, los cuales ya llevan varias décadas. Estos pretendían responder a cuestionamientos propios de su época.

Sin embargo, no nos cansamos de ver y subrayar en ellos su actualidad; recurrimos a estos a menudo y percibimos que aún tienen mucho que ofrecer a la Iglesia. Este es el caso de la Constitución Dogmática Lumen Gentium (LG), 
documento magisterial significativo y central entre los textos emanados del Concilio Vaticano II.

La LG, como lo decían los obispos en el Sínodo extraordinario de 1985, que tuvo como título: "Vigésimo aniversario de las conclusiones del Concilio Vaticano II", incorpora a las otras Constituciones conciliares. En todas ellas la Iglesia es el tema central y hacia ella se orientan. Así, la Iglesia iluminada por la Palabra de Dios, celebra los misterios de Cristo para la salvación del mundo.

La LG es por excelencia la constitución Eclesial; ella es fruto de un largo camino y de búsquedas para llegar a presentar, de una manera renovada, el rostro de una Iglesia que pretende pasar de la concepción de Iglesia sociedad perfecta a una Iglesia en comunión y en camino hacia la santidad; de una Iglesia identificada con la jerarquía a una comunidad con identidad de pueblo de Dios; de una Iglesia de pastores y de grey, de docentes y dicentes a una comunidad de hermanos y hermanas en la que todos colaboran en su construcción y todos la evidencian con su testimonio.

Es interesante recordar que dentro del proceso que siguió a la elaboración del documento se presentó un esquema preparatorio en 11 capítulos que comprendía: la naturaleza de la Iglesia militante, los miembros de la Iglesia militante y necesidad de la misma para la salvación, el episcopado como grado supremo del orden y del sacerdocio, los obispos residenciales, los estados de perfección evangélica, los seglares, el Magisterio de la Iglesia, autoridad obediencia de la Iglesia, las relaciones entre la Iglesia y el Estado, la obligación que tiene la Iglesia de anunciar el Evangelio a todos los pueblos y en toda la tierra y el ecumenismo.

Luego de varias redacciones se llegó al texto final en el cual el lenguaje es un poco diferente y, podríamos decir, más incluyente y pastoral. Así, el documento que fue aprobado consta de 69 números distribuidos en ocho capítulos bajo los siguientes títulos: El misterio de la Iglesia (1-8); El pueblo de Dios (9-17); Constitución jerárquica de la Iglesia y particularmente del episcopado (18-29); Los laicos (30-38); Universal vocación a la santidad en la Iglesia (39-42); Los religiosos (43-47); Índole escatológica de la Iglesia peregrinante y su unión con la Iglesia celestial (48-42) y; La santísima Virgen, Madre de Dios, en el misterio de Cristo y de la Iglesia (52-69).

Lo dicho en el numeral 1 de la Constitución marca una síntesis del Concilio y de este documento: Cristo es la Luz del mundo. Queda claro que la misión de toda la Iglesia es iluminar con la luz que procede de Cristo y no de ella misma puesto que solo cumple un papel mediador. Ella como Juan el Bautista es testigo de la Luz verdadera: 
Apareció un hombre enviado por Dios, llamado Juan, que vino como testigo, para dar testimonio de la luz, de modo que todos creyeran por medio de él. Él no era la luz, sino un testigo de la luz. La luz verdadera que ilumina a todo hombre estaba viniendo al mundo. (Jn 1,6-9)

El recorrido a través de estos capítulos atañe a todos los miembros de la comunidad de creyentes y su misión respectiva; busca responsabilizarnos a todos, sin excepción, de esta Luz y de su transmisión, sin perder de vista que la unidad de los miembros de la Iglesia es primordial para que el Evangelio irradie a todo el mundo.

Deseo invitarlos para que a través de tres momentos nos acerquemos a la Lumen Gentium y hagamos el vínculo con la Palabra de Dios: Biblia e Iglesia, las imágenes bíblicas de la Iglesia y el paso de una pastoral de mera conservación a una pastoral decididamente misionera.

\section{Biblia e Iglesia}

Para esta reflexión presentamos la relación existente entre Biblia e Iglesia. Y tendríamos que iniciar subrayando que la fundamentación bíblica de la LG es bastante fuerte. Las citas explicitas e implícitas son numerosas y recurren sobre todo a textos del Nuevo Testamento en los que Jesucristo es el centro.

Por ejemplo el documento hace referencia al Reino de Dios en el número 5 y afirma: "Pero, sobre todo, el Reino se manifiesta en la Persona del mismo Hijo del Hombre, que vino «a servir, y a dar su vida para redención de muchos» (Mc 10,45)". Esta Constitución dogmática se abre con una afirmación: “Cristo es la luz de los pueblos" (LG, 1) e invita a todos los hombres a conseguir la plena unidad en Él.

Es indiscutible que no podemos separar el binomio Biblia e Iglesia o si preferimos, podríamos decir, Palabra de Dios y comunidad de creyentes. La Escritura sin una comunidad que la lea, la profundice, la asimile, la actualice y la haga vida sería simplemente un libro más. De la misma manera una comunidad eclesial que marche al margen de la Palabra se convertiría en un grupo cualquiera.

Recordemos las palabras de Pablo en la carta a Timoteo:

Toda Escritura es inspirada y útil para enseñar, argumentar, encaminar e instruir en la justicia. Con lo cual el hombre de Dios estará formado y capacitado para toda clase de obras buenas (2Tm 3, 16-17).

Como dice el padre Toribio Tapia Bahena, sacerdote Mexicano: 
La Biblia nacida en la comunidad, vuelve a ella para edificarla, para servirle como alimento y acompañarla en la misión permanente de dar testimonio de su fe hasta el final de los tiempos. (Tapia, 2000, p. 13)

La comunidad cristiana, en sus inicios, se fundó en torno a la persona de Jesús de Nazaret y su predicación; en medio de dudas y convicciones, entre miedos y parresia, entre certezas e incertezas y gracias a la relectura atenta de las Escrituras, los primeros discípulos fueron descubriendo que el Maestro, al que habían seguido y amado, era el Mesías del que hablaban las profecías. Así el mensaje de la cruz, como dice Pablo a los corintios, es fuerza de Dios: "Porque el mensaje de la cruz es locura para los que se pierden; pero para los que nos salvaremos es fuerza de Dios." (1Co 1, 18).

Si la Escritura no hubiera sido retomada por los discípulos, leída e interpretada en clave mesiánica y Pascual, muy seguramente no habrían captado que el rabí, Jesús de Nazaret, era el Hijo de Dios, el Salvador, el esperado de los tiempos. El evangelio de Lucas así lo confirma:

Y comenzando por Moisés y siguiendo por todos los profetas, les interpretó lo que en toda la Escritura se refería a él (Lc 24, 27).

Esto es lo que les decía cuando todavía estaba con ustedes: que tenía que cumplirse en mí todo lo escrito en la Ley de Moisés, en los profetas y en los Salmos. Entonces les abrió la inteligencia para que comprendieran la Escritura. (Lc 24, 44-45).

Y el evangelio de Juan coloca en boca de Felipe una frase emblemática en el momento en que convoca a Natanael para que descubra quien es Jesús de Nazaret: "Felipe encuentra a Natanael y le dice: - Hemos encontrado al que describen Moisés en la ley y los profetas: Jesús, hijo de José, el de Nazaret." (Jn 1, 45).

Así podemos afirmar que la comunidad cristiana tuvo su origen en la figura de Jesús, en sus acciones y en sus palabras, como lo afirma la Dei Verbum: Dios se revela en hechos y palabras (DV, 2). Este descubrimiento se hace también desde la relectura asidua y profunda del Antiguo Testamento en clave mesiánica o, como acostumbramos decir, en clave tipológica. Así Jesús es para los creyentes el principio de unidad eclesial.

El numeral nueve de la LG lo expresa de la siguiente manera:

La congregación de todos los creyentes que miran a Jesús como autor de la salvación y principio de la unidad y de la paz, es la Iglesia convocada y constituida por Dios, para que sea para todos y cada uno sacramento visible de esta unidad salvífica. (LG. 9) 
El recurso a la Escritura fue clave en la naciente comunidad cristiana, y lo continúa siendo hoy. La meditación asidua de la Palabra permite el encuentro con nuestro Salvador y el conocimiento de Jesucristo, tal como lo afirma san Jerónimo en el prólogo al comentario de Isaías: Desconocer las Escrituras es desconocer a Cristo (DV, 25). No se trata solo de una lectura de la Biblia que lleve a la información o a saber mucho, sino de un acercamiento que permita comprender el mensaje de la Escritura y posibilite el que sea llevado a la práctica para renovar la vida personal y comunitaria.

El evangelista Juan coloca en boca de Jesús, después de la multiplicación de los panes, un cuestionamiento a quienes van tras él, el mismo que hace que nos preguntemos sobre nuestras motivaciones y acercamientos a la Palabra: "Les aseguro que no me buscan por las señales que han visto, sino porque se han hartado de pan" (Jn 6, 26).

Esta frase de Jesús interroga nuestra manera de relacionarnos con la Escritura en Iglesia: bien podemos ser comunidades cristianas llenas de Biblia, hartas de Palabra, con muchos cursos de Sagrada Escritura, bien informados sobre ella, pero sin darle la oportunidad de ejercer su poder transformador. La cultura bíblica no basta; es necesario hacer vida la Escritura, ello consiste no tanto en atravesar el libro de pasta a pasta sino más bien en que el contenido del libro nos atraviese, nos haga más humanos y nos disponga a ser más hermanos. Pues según la carta a los hebreos:

Porque la Palabra de Dios es viva y eficaz y más cortante que espada de dos filos; penetra hasta la separación de alma y espíritu, articulaciones y médula, y discierne sentimientos y pensamientos del corazón. No hay criatura oculta a su vista, todo está desnudo y expuesto a sus ojos. A ella rendiremos cuentas. (Heb 4, 12-13)

Retomando el numeral 14 del documento conciliar que habla de la universalidad y catolicidad de todo el pueblo de Dios podríamos decir que cada una de las partes que conforman la comunidad eclesial recibe la fuerza de la Palabra de Dios, la hace vida y a su vez la comunica a los otros:

En virtud de esta catolicidad cada una de las partes presenta sus dones a las otras y a toda la Iglesia, de suerte que el todo y cada uno de sus elementos se aumenta con todos los que mutuamente se comunican y tienden a la plenitud en la unidad.

Esta unidad está cimentada en la fuerza de la Palabra que mueve a cada miembro de la Iglesia y que es motor que lleva acciones concretas en bien de la 
humanidad. Jesucristo nos convoca a ser uno: "Que todos sean uno, como tú, Padre, estás en mí y yo en ti; que también ellos sean uno en nosotros, para que el mundo crea que tú me enviaste" (Jn 17, 21). Un cristiano, un católico, es un hombre movido por la Palabra que lo conduce a actuar responsablemente en su entorno social y pone al servicio de la humanidad sus dones, como nos lo recuerda Mateo 25 sobre el juicio de las naciones:

Entonces el rey dirá a los de la derecha: Vengan, benditos de mi Padre, a recibir el reino preparado para ustedes desde la creación del mundo. Porque tuve hambre y me dieron de comer, tuve sed y me dieron de beber, era emigrante y me recibieron, estaba desnudo y me vistieron, estaba enfermo y me visitaron, estaba encarcelado y me vinieron a ver. Los justos le responderán: Señor, ¿cuándo te vimos hambriento y te alimentamos, sediento y te dimos de beber, emigrante y te recibimos, desnudo y te vestimos? ¿Cuándo te vimos enfermo o encarcelado y fuimos a visitarte? El rey les contestará: Les aseguro que lo que hayan hecho a uno solo de éstos, mis hermanos menores, me lo hicieron a mí (Mt 25, 34-40).

\section{Las imágenes bíblicas de la Iglesia}

A lo largo de la historia, la Iglesia ha tomado metáforas bíblicas para autodefinirse; estas figuras aún hoy son actuales pues no pierden su fuerza, de la misma manera que la Escritura nunca pierde su vigor. En la LG, en los numerales 5 y 6 , encontramos una serie de figuras o imágenes bíblicas que la Iglesia se ha apropiado y que se han convertido, a través de los siglos, como en logotipos que hablan de su vocación y misión.

Podríamos decir que necesitamos revisarlas y ver si la Iglesia es fiel a lo que ella se dice a sí misma y anuncia a los demás.

Del mismo modo que en el Antiguo Testamento la revelación del reino se propone frecuentemente en figuras, así ahora la naturaleza íntima de la Iglesia se nos manifiesta también mediante diversas imágenes tomadas de la vida pastoril, de la agricultura, de la edificación, como también de la familia y de los esponsales, las cuales están ya insinuadas en los libros de los profetas. (LG, 6)

Nos detendremos, de manera particular, en cuatro de estas imágenes: la Iglesia como un redil, inserta en el tronco de Israel, como una viña y como una edificación. 


\section{La Iglesia como un redil y una grey:}

A partir del evangelio de Juan, en el capítulo décimo, la LG inicia su enumeración de figuras:

Así la Iglesia es un redil, cuya única y obligada puerta es Cristo (cf. Jn 10,1-10). Es también una grey, de la que el mismo Dios se profetizó Pastor (cf. Is 40,11; Ez 34,11ss), y cuyas ovejas, aunque conducidas ciertamente por pastores humanos, son, no obstante, guiadas y alimentadas continuamente por el mismo Cristo, buen Pastor y Príncipe de los pastores (cf. Jn 10, 11; 1P 5, 4), que dio su vida por las ovejas. (cf. Jn 10, 11-15)

¿Qué significa que la Iglesia se considere a sí misma como un redil? Esta figura pastoril no solo ha marcado la comunidad cristiana, sino que también ha sido fuertemente empleada por el pueblo judío. Se habla de grey no tanto por que las personas que forman dichos grupos de creyentes sean consideradas como ovejas, sino más bien, porque se ve el rol imprescindible del pastor, del guía, del conductor.

La LG insiste en el capítulo segundo sobre la dimensión de Pueblo de Dios, supera la idea de sociedad perfecta, al brindar elementos que nos ayudan a ir más allá de la dualidad que por siglos ha trastornado las relaciones eclesiales: clero y laicos. Muy evangélicamente la LG afirma nuestro sacerdocio común; somos miembros de una comunidad de hermanos y hermanas bajo la guía de un único Pastor: Jesucristo. En este punto vale la pena preguntarse ¿qué rol juega la Escritura en el seno de la comunidad creyente que se considera el rebaño del Señor?

Una comunidad que está animada por la Palabra es una comunidad que escucha en ella la voz del Pastor y descubre los llamados permanentes a renovarse y a ponerse en camino. Así, se puede afirmar que la Palabra de Dios que es leída en el seno de la comunidad eclesial, es una Palabra escrita que lleva a los oyentes a superar el estadio de la mera información para entrar en el camino del discípulo.

Es innegable que hoy todos los que hacemos parte de la Iglesia conocemos las Escrituras, o al menos tenemos contacto con la Biblia; sin duda los encargados de las iglesias locales y de las parroquias, haciendo eco de los documentos magisteriales tanto universales como regionales, se preocupan por formar a los fieles en estudios bíblicos. Por otro lado, los agentes de pastoral son cada día más capacitados en el estudio de las Escrituras. Se crean centros de formación bíblica y el estudio de Teología y de la Sagrada Escritura es abierto a todo fiel que lo desee. 
Pero, quizás el riesgo es quedarnos con mucho saber, bastante información y poca vivencia de la Palabra de Dios. La Palabra, para ser eficaz, debe llegar a transformar nuestras existencias, como dice el deutero-Isaías:

Como bajan la lluvia y la nieve del cielo, y no vuelven allá, sino que empapan la tierra, la fecundan y la hacen germinar, para que dé semilla al sembrador y pan para comer, así será mi Palabra, que sale de mi boca: no volverá a mí vacía, sino que hará mi voluntad y cumplirá mi encargo $(55,10-11)$.

\section{Dos figuras interesantes: la Iglesia inserta en el tronco de Israel y la viña:}

La LG, no solo emplea la imagen pastoril, ella aborda también imágenes de la agricultura; particularmente toma de las plantas y de los árboles la imagen del olivo y de la vid. Presenta a la Iglesia como una labranza, o arada de Dios (cf. 1Co 3, 9).

En ese campo crece el vetusto olivo, cuya raíz santa fueron los patriarcas, y en el cual se realizó y concluirá la reconciliación de los judíos y gentiles (cf. $R m$ 11, 13-26). El celestial Agricultor la plantó como viña escogida (cf. Mt 21, 33-34 par.; cf. Is 5, 1 ss). La verdadera vid es Cristo, que comunica vida y fecundidad a los sarmientos, que somos nosotros, que permanecemos en El por medio de la Iglesia, y sin El nada podemos hacer. (cf. Jn 15, 1-5)

La figura del Olivo que simboliza el tronco de Israel, que el documento llama vetusto, al que el cristianismo está injerto, al igual que la imagen de la vid, son claves para adentrarse en dos realidades de la vida de la Iglesia. La primera nos lleva a ver nuestros orígenes como comunidad creyente y la segunda a revisar la concepción que tenemos de nosotros mismos como comunidad. Es oportuno dar una mirada más detallada a estas:

\subsection{El olivo en el que estamos injertos.}

Un punto relevante entre estas imágenes de plantas está dado por la LG al retomar el texto de Rm 11, elemento clave en la concepción de Iglesia y fundamental para el diálogo judeocristiano. Como es sabido tanto la declaración conciliar Nostra Aetate como la declaración dogmática Dei Verbum, son textos relevantes que evidencian la necesidad de acercarnos a la tradición del pueblo judío dentro del 
aire renovador que impulsaba los estudios bíblicos. Prueba de ello es la declaración conciliar sobre el diálogo con otras religiones:

Ella marca un giro decisivo en las relaciones Iglesia - Sinagoga e invita a no olvidar, como dice san Pablo, que la Iglesia se nutre del buen olivo en que se han injertado las ramas del olivo silvestre que son los gentiles.

El numeral 4 de Nostra Aetate, es considerado el texto clave para el reinicio oficial de una nueva época de las relaciones judeocristianas; este numeral, especialmente consagrado a la religión judía, recalca que si bien durante la pasión, las autoridades judías y sus seguidores motivaron la muerte de Jesús, esto no puede ser imputado a los judíos de la época, ni a los judíos de hoy. El pueblo judío no puede seguir siendo condenado como autor de la muerte de Cristo, ni debe continuar siendo representado como maldito. (Vergara, 2014, pp. 22-23)

De aquí que la mención, aunque rápida y que puede pasar desapercibida, del capítulo 11 de la carta a los Romanos, en el documento conciliar, solicite atención. El apóstol Pablo no deja de lado a su pueblo judío. Emplea dos alegorías, la de la masa consagrada y la del olivo a cuyo tronco estamos injertos los cristianos, en las que manifiesta que el judaísmo no es rechazado.

Estas dos comparaciones paralelas ilustran la relación de una parte privilegiada con el resto. Consagrar las primicias era un rito que consagraba la totalidad, era reconocer la fecundidad de la tierra como don de Dios. La raíz es lo "radical que define la naturaleza del árbol." (Alonso Schökel, 1996, p. 404)

Así se puede decir con Pablo que el resto de Israel es consagrado porque sus antepasados lo fueron, lo mismo los cristianos los son pues están como ramas injertas en el gran tronco del árbol ya consagrado. Los cristianos no salieron de la nada, ni son los primeros, son herederos de una tradición. El pueblo de Israel ha sido comparado con el olivo y llamado de manera particular el olivo de Dios. Esta analogía resulta natural dado que el olivo es el árbol más conocido y corriente en la región mediterránea. (Vergara, 2014, p. 23)

Recordemos que la Pontificia Comisión Bíblica, en el documento titulado "La interpretación de la Biblia en la Iglesia" publicado en 1993, presenta como válido el acercamiento a la Sagrada Escritura desde la exégesis judía. De igual forma brindó, en 2001, un texto llamado: El pueblo judío y sus Escrituras sagradas, en la Biblia cristiana, aún desconocido por la mayoría de fieles, que invita a reavivar los vínculos fraternos que unen al judaísmo y al cristianismo. 
Este último documento constata que la lectura judía de la Biblia es una lectura posible que está en continuidad con las Sagradas Escrituras de los judíos del tiempo del segundo Templo y es análoga a la lectura cristiana que se ha desarrollado en paralelismo con ella. (Pontificia Comisión Bíblica, 2001). Añade que los cristianos pueden aprender mucho de la exégesis judía practicada durante 2000 años, y viceversa. Los cristianos pueden confiar en que los judíos podrán sacar provecho de las investigaciones de la exégesis cristiana.

Así pues, es indiscutible que los cristianos, ramas injertas en el tronco del olivo de Israel, no podemos menospreciar nuestras raíces sino, al contrario, conocerlas cada día más para que, de esta manera, descubramos la riqueza que portamos como hermanos menores del pueblo judío, tal como lo decía el papa Juan Pablo II (2005), para que agradezcamos a Dios, nuestro padre común, por la savia que de este tronco bebemos.

\subsection{La Iglesia como una vid.}

Esta es otra de las metáforas bíblicas, a la que es importante dedicarle un tiempo de reflexión. Este pasaje hace parte de los discursos de adiós del evangelio de Juan. Vale la pena preguntarnos si el texto bíblico nos presenta una alegoría, un mashal, una alocución gráfica, una metáfora o si este es simplemente un recurso joánico. Este pasaje ha sido llamado de varias formas, pero lo que verdaderamente nos interesa es que esta vid es una imagen importante que hace parte de la tradición religiosa de Israel.

En los textos de la Primera Alianza Israel es representada como la parra o la viña de Dios. Isaías en 5, 1-7 dice que "La viña del Señor de los ejércitos es la casa de Israel" y Jeremías en 2, 21 lo confirma: "Yo te planté de pura cepa". Ezequiel en el capítulo 15 va aún más lejos en su afirmación de que la madera de esta vid solo sirve para el fuego y en Ez 19, 10-14 nos dice que Israel es como con una parra arrojada al desierto.

Oseas 10, 1 también hace referencia a esta imagen al decir: "Israel es una frondosa parra" y el Salmo 80, 8 lo resalta: "Te trajiste una vid de Egipto". La vid simboliza la nación de Israel y ya en las monedas de la época macabea aparecía como emblema. Por otro lado, la gran vid de oro se hallaba esculpida en la fachada del Templo de Jerusalén y era un honor ofrecer el metal precioso para una uva de aquel racimo emblemático.

Pero recordemos que en boca de los profetas el comparar al pueblo de Israel con la vid, más que un elogio era una denuncia. Para ellos el pueblo de Dios había perdido su vocación, ya no daba frutos y ya no servía más que para ser arrojado al fuego. 
Esto que hemos enunciado sobre la imagen de la vid nos invita a preguntarnos ¿por qué Jesús se autodenomina la Vid auténtica, si el prestigio de esta imagen no era tan favorable para los hombres de Dios? Al parecer esto es una burla para la tradición pues el símbolo de la vid se emplea en el Antiguo Testamento unido a la idea de decadencia de la nación y de su religiosidad.

Según los profetas Dios se lamenta de su pueblo porque la viña plantada por él no da fruto. Sus sarmientos no son buenos ni están sanos. Quizás en este sentido va la metáfora del evangelista Juan puesta en boca de Jesús, pues al parecer es una denuncia en la línea profética contra quienes se creen sarmientos verdaderos; el hecho de ser miembro de la nación judía no salva a nadie. Resulta interesante esta imagen que los padres conciliares aplican a la Iglesia; a lo mejor el citar el cuarto evangelio sea también una posibilidad de recorrer lo dicho por los profetas y esto permita que nos cuestionemos como comunidad creyente. Puede ser que el reproche hecho a Israel también nos alcance a nosotros.

Fácilmente la Iglesia y sus miembros se pueden convertir en sarmientos improductivos cuando la Palabra es oída pero no pasa a la vida; cuando se confiesa o se profesa a Jesucristo como Señor y no hay acciones que muestren nuestra fe; cuando decimos que él es nuestro Maestro y no nos comportamos como discípulos. El sarmiento improductivo termina su carrera en el fuego. Este es un llamado a la Iglesia en general, y una invitación a todos sus miembros en particular, a pertenecer y a permanecer en Cristo.

\section{La Iglesia como una edificación de Dios:}

La imagen de la edificación o de la casa es una figura llena de gran contenido comunitario no solo, porque habla de quienes la habitan o entran en ella, sino sobre todo porque ella hace pensar en los materiales con que se construye. Ya el salmo 126 lo expresa claramente, el constructor es el Señor, si él no la construye en vano se cansan los albañiles.

A veces también la Iglesia es designada como edificación de Dios (cf. 1 Co 3,9). El mismo Señor se comparó a la piedra que rechazaron los constructores, pero que fue puesta como piedra angular (cf. $M t$ 21,42 par.; Hch 4,11; 1 P 2,7; Sal 117,22). Sobre este fundamento los Apóstoles levantan la Iglesia (cf. 1 Co 3,11) y de él recibe esta firmeza y cohesión. Esta edificación recibe diversos nombres: casa de Dios (cf. 1 Tm 3,15), en que habita su familia; habitación de Dios en el Espíritu (cf. Ef 2,19-22), tienda de Dios entre los hombres (Ap 21,3) y sobre todo templo santo, 
que los Santos Padres celebran como representado en los templos de piedra, y la liturgia, no sin razón, la compara a la ciudad santa, la nueva Jerusalén []ㅡ. Efectivamente, en este mundo servimos, cual piedras vivas, para edificarla (cf. 1 P 2,5). San Juan contempla esta ciudad santa y bajando, en la renovación del mundo, de junto a Dios, ataviada como esposa engalanada para su esposo. (Ap 21,1 s)

Construir juntos la casa común, que es la Iglesia, pide que al participar todos de esta obra, como dice la carta de Pedro, nos dispongamos como piedras vivas a estar al lado de otros en una construcción de la que somos responsables. Allí cada uno ocupa su lugar y de todos depende la solides de la construcción. La condición es estar unidos a la Piedra Viva y angular que es Cristo (cf. 1Pe 2, 4-5).

\section{De una pastoral de mera conservación a una pastoral decididamente misionera $(\mathrm{Ap}, \mathrm{370})$}

En este tercer punto de la reflexión quisiera hacer eco de esta frase del Documento de Aparecida que se encuentra en el número 370, y que es retomada por el Papa Francisco en la Evangelii Gaudium, invitándonos a desinstalarnos:

La conversión pastoral de nuestras comunidades exige que se pase de una pastoral de mera conservación a una pastoral decididamente misionera. Así será posible que el único programa del Evangelio siga introduciéndose en la historia de cada comunidad eclesial con nuevo ardor misionero, haciendo que la Iglesia se manifieste como una madre que sale al encuentro, una casa acogedora, una escuela permanente de comunión misionera. (Ap, 370)

El llamado del documento de Aparecida es una convocación clara a entrar en otro paradigma de Iglesia, como lo afirma también el Nuevo Plan Pastoral de la Arquidiócesis de Bogotá:

¿Qué sucedería si nos tomáramos realmente en serio esas palabras? Simplemente reconoceríamos que la salida misionera es el paradigma de toda obra de la Iglesia. En esta línea, los Obispos latinoamericanos afirmaron que ya «no podemos quedarnos tranquilos en espera pasiva en nuestros templos» y que hace falta pasar «de una pastoral de mera conservación a una pastoral decididamente misionera». 
Esta tarea sigue siendo la fuente de las mayores alegrías para la Iglesia: «Habrá más gozo en el cielo por un solo pecador que se convierta, que por noventa y nueve justos que no necesitan convertirse» (Lc 15,7). $(\mathrm{EG}, 15)$

Sin duda que este paso solo es posible si atentos a la Palabra de Dios nos dejamos renovar e impulsar por ella. Pues como dice Pablo en la carta a los romanos:

Pero, ¿cómo lo invocarán si no han creído en él? ¿Cómo creerán si no han oído hablar de él? ¿Cómo oirán si nadie les anuncia? ¿Cómo anunciarán si no los envían? Como está escrito: ¡Qué hermosos son los pasos de los mensajeros de buenas noticias! Sólo que no todos responden a la Buena Noticia. Isaías dice: Señor, ¿quién creyó nuestro anuncio? La fe nace de la predicación, y lo que se proclama es el mensaje de Cristo. (Rm 10, 14)

El Papa Francisco nos lo recuerda con frecuencia y nos insiste que una Iglesia en salida es una Iglesia en la que la Palabra dinamiza y en la que la alegría del Evangelio hace misioneros. También nos dice que la Palabra lleva en si una fuerza capaz de transformarnos si lo deseamos.

La Palabra tiene en sí una potencialidad que no podemos predecir. El Evangelio habla de una semilla que, una vez sembrada, crece por sí sola también cuando el agricultor duerme (cf. Mc 4,26-29). La Iglesia debe aceptar esa libertad inaferrable de la Palabra, que es eficaz a su manera, y de formas muy diversas que suelen superar nuestras previsiones y romper nuestros esquemas. (EG, 22)

La Iglesia, a través de sus pastores, viene desde hace algún tiempo invitándonos a realizar una animación bíblica de la pastoral en la que la Biblia sea el centro de la acción misionera, tal como lo sugiere el Documento de Aparecida:

Los discípulos de Jesús anhelan nutrirse con el Pan de la Palabra: quieren acceder a la interpretación adecuada de los textos bíblicos, a emplearlos como mediación de diálogo con Jesucristo, y a que sean alma de la propia evangelización y del anuncio de Jesús a todos. Por esto la importancia de una "pastoral bíblica", entendida como animación bíblica de la pastoral, que sea escuela de interpretación o conocimiento de la Palabra, de comunión con Jesús u oración con la Palabra, y de evangelización inculturada o de proclamación de la Palabra. Esto exige por parte de obispos, presbíteros, diáconos y ministros laicos de la Palabra un acercamiento a la Sagrada Escritura que no sea sólo intelectual e 
instrumental, sino con un corazón "hambriento de oír la Palabra del Señor" (Am 8,11). (DA, 248)

Este hermoso numeral se constituye en la fundamentación clave para hablar de animación bíblica de la pastoral en la acción evangelizadora de la Iglesia, así lo recupera el Papa Benedicto XVI en la Exhortación Apostólica Verbum Domini:

En este sentido, el Sínodo ha invitado a un particular esfuerzo pastoral para resaltar el puesto central de la Palabra de Dios en la vida eclesial, recomendando «incrementar la "pastoral bíblica", no en yuxtaposición con otras formas de pastoral, sino como animación bíblica de toda la pastoral». No se trata, pues, de añadir algún encuentro en la parroquia o la diócesis, sino de lograr que las actividades habituales de las comunidades cristianas, las parroquias, las asociaciones y los movimientos, se interesen realmente por el encuentro personal con Cristo que se comunica en su Palabra. Así, puesto que «la ignorancia de las Escrituras es ignorancia de Cristo», la animación bíblica de toda la pastoral ordinaria y extraordinaria llevará a un mayor conocimiento de la persona de Cristo, revelador del Padre y plenitud de la revelación divina. Por tanto, exhorto a los pastores y fieles a tener en cuenta la importancia de esta animación: será también el mejor modo para afrontar algunos problemas pastorales puestos de relieve durante la Asamblea sinodal, y vinculados, por ejemplo, a la proliferación de sectas que difunden una lectura distorsionada e instrumental de la Sagrada Escritura. Allí donde no se forma a los fieles en un conocimiento de la Biblia según la fe de la Iglesia, en el marco de su Tradición viva, se deja de hecho un vacío pastoral, en el que realidades como las sectas pueden encontrar terreno donde echar raíces. (DV, 73)

Es decir que estamos llamados a pasar de una popularización del texto bíblico que consiste en multiplicar y distribuir Biblias, en hacer cursos y formaciones bíblicas, que sin duda fueron y son de gran ayuda, a una acción pastoral en la que la Escritura permee todas las actividades y se convierta en el alma de la evangelización, con lo que se responde al llamado del Concilio Vaticano II en la Dei Verbum número 21.

Por esta y otras razones, la pastoral bíblica se plantea hoy de modo diverso: como animación bíblica de la pastoral o de la labor evangelizadora de la Iglesia. Y no se trata solo de un cambio de nombre o de un énfasis sin mayor importancia, sino de un cambio de mentalidad en 
orden a animar el discipulado misionero y el servicio de la Iglesia en el mundo. (Silva, 2013, p. 143)

La animación bíblica de la pastoral es ante todo el medio por el cual la Palabra se convierte en el alma de toda la acción eclesial para que ella sea, como dice el Papa Benedicto XVI en la Verbum Domini 1: "El corazón de toda actividad eclesial".

\section{Conclusión}

Para concluir esta reflexión sobre la interacción, sólida y armoniosa, entre Biblia e Iglesia es oportuno subrayar que nuestra iglesia local de la Arquidiócesis de Bogotá ha tomado como texto evangélico e imagen bíblica inspiradora la que nos brinda el evangelio de Mateo en 5, 13: Ustedes son la sal de la tierra. Ustedes son la luz del mundo.

En la Escritura encontramos gran variedad de recursos metafóricos que utiliza Jesús para referirse tanto a la presencia del reino de Dios, al significado de la relación de la Iglesia con el mundo y al modo de ser discípulos suyos. Para el caso de la arquidiócesis de Bogotá las imágenes de "sal de la tierra" y "luz del mundo", luego de un proceso de discernimiento en la construcción del plan de evangelización, se ven como aquellas que pueden orientar el ser y hacer de la Iglesia hoy. Son imágenes que van a permitir a la arquidiócesis de Bogotá realizar con fidelidad su vocación y misión de ser "sacramento" de salvación. (Arquidiócesis de Bogotá, 2015, p. 58)

Estas imágenes motivan a la Iglesia a redescubrir su vocación y su misión ayudándola, como dice el documento sobre el Paradigma de evangelización en la Arquidiócesis, a comprender y a asumir la Iglesia que Dios quiere y que la ciudad necesita (p. 59). 


\section{Referencias}

Alonso Schökel, L. (1996). La Biblia del Peregrino. Edición de estudio. Tomos I, II y III. Bilbao: Ega-Mensajero-Verbo Divino.

Arquidiócesis de Bogotá, (2015). El paradigma de la evangelización en la arquidiócesis de Bogotá. Bogotá: San Pablo.

Celam, (2007). V Conferencia General del Episcopado Latinoamericano y del Caribe. Documento conclusivo [Aparecida]. Bogotá: Celam.

Concilio Vaticano II. (2000). Declaración Nostra Aetate. Bogotá: San Pablo.

Concilio Vaticano II. (2000). Constitución dogmática Dei Verbum. Bogotá: San Pablo.

Concilio Vaticano II. (2000). Constitución dogmática Lumen Gentium. Bogotá: San Pablo.

Juan Pablo II, (2005). Prière pour le peuple juif. Yerushalaim 40: 13.

Pontificia Comisión Bíblica, (24 de mayo de 2001). El pueblo judío y sus Escrituras sagradas en la Biblia cristiana. Recuperado de: http// www.vatican.va/ roman_curia/congregations.

Silva, S. (2013). La Palabra de Dios en la Iglesia y en su actividad eclesial. Bogotá: Celam.

Tapia Bahena, T. (2000). La biblia y la comunidad creyente, La Palabra Hoy XXV, N 95 [pp. 13-44]. Bogotá: Federación Bíblica Católica.

Vergara, A. (2014). Abrir la Biblia cristiana en clave judía, Midrash y Targum una manera de interpretar. Bogotá: Javegraf. 